\title{
A low-force swivel connector for infusing liquids into unrestrained animals
}

\author{
PHILIP W. WIRTH, W. F. CROWDER, and JOHN A. BEDFORD \\ University of Mississippi, University, Mississippi 38677
}

\begin{abstract}
A swivel connector for infusing liquids into catheterized animals is described. The connector turns so freely that restraints and strain relief for the catheter are unnecessary. A cylindrical acrylic body and nylon cap screw hold a rubber $O$ ring in place, and a length of needle tubing rotates within the $O$ ring. The only friction in the swivel is between the needle tubing and the interior of the $O$ ring. Construction time is about $1 \mathrm{~h}$. Swivels of this design have provided trouble-free service for 3 years.
\end{abstract}

The swivel connector described in this paper was originally designed to infuse drug solutions into conscious rats with chronically implanted catheters. In order to test the rats without restraints or saddles, we designed a swivel that turns with less force than the force necessary to twist the PE 20 tubing used in the catheters. The only moving part in the swivel is a length of 20 -g needle tubing, and the only point of friction is the contact between the needle tubing and the interior of a small $O$ ring. With the proper tools and materials available, the swivel can be built in $1 \mathrm{~h}$. The cost of materials per unit is about $\$ 2$. The swivel can be cleaned and sterilized with disinfectant solutions, but it is not autoclavable.

We have used this swivel with rats and monkeys continuously for 3 years with no leakage or jamming. The only maintenance necessary is to occasionally disassemble and clean the swivels.

\section{CONSTRUCTION}

The swivel has three parts: a swivel body, a rotating tube, and a screw cap. The necessary materials are listed in Table 1. Drill and screw sizes are U.S. standard; metric construction materials were not available. Approximate metric equivalents are as follows: No. 37 drill $=2.64-\mathrm{mm}$ diam, No. $55=1.32 \mathrm{~mm}$, No. $56=1.18 \mathrm{~mm}$, No. $60=$ $1.02 \mathrm{~mm}, 6.32$ screw size $=3.51 \mathrm{~mm}$ OD with 12.6 turns $/ \mathrm{cm}$.

\section{Swivel Body}

To construct the swivel body, drill a hole $13 \mathrm{~mm}$ deep in the long axis of the acrylic rod with a No. 37 drill. Then drill the rest of the way through the rod with a No. 60 drill. Care should be taken that the holes are parallel and concentric. Thread the larger hole to a depth

Development of this device was supported in part by U.S. Public Health Service Grant MH 13570, awarded to Dr. W. F. Crowder. Thanks are expressed to Dr. James C. Murphy for several valuable suggestions regarding the manuscript. Drs. Wirth and Bedford are now at the Research Institute of Pharmaceutical Sciences, School of Pharmacy, University of Mississippi, University, Mississippi 38677 .

of $11 \mathrm{~mm}$ with a 6-32 taper tap, followed by a 6-32 bottoming tap. Remove all plastic chips, preferably with a high-pressure air blast. Lubricate the $O$ ring with a small amount of stopcock grease and gently force it to the bottom of the hole with the blunt end of a No. 37 drill. The hole in the $O$ ring should be visible in the center of the No. 60 drill hole, showing that the large and small holes are concentric.

\section{Rotating Tube}

The rotating tube is simply a $19-\mathrm{mm}$ length of $20-\mathrm{g}$ thin-wall hypodermic tubing that has been flared at one end using a center punch. The tubing can be flared easily if held in a No. 60 drill hole in a block of plastic or metal. The washer is slipped onto the rotating tube and it is inserted, nonflared end first, through the $O$ ring so that the flared end and the washer rest in the No. 37 drill hole.

\section{Screw Cap}

A No. 56 drill is used to make a hole lengthwise through the nylon screw. This can be done quite easily

Table 1

Materials Used to Construct Swivel

Buna-N-rubber O-ring, .8-mm (1/32-in.) I.D. and 2.4-mm (3/32-in.) O.D.

Stainless steel flat washer, size 000

Nylon binder head machine screw, size $6-32$ cut to $12.7-\mathrm{mm}$ (1/2-in.) length

$18 \mathrm{~g}$ hypodermic tubing, cut to 19-mm length

$20 \mathrm{~g}$ thin wall hypodermic tubing, cut to $19-\mathrm{mm}$ length

12.7-mm (1/2-in.) diam clear acrylic rod, cut to $19-\mathrm{mm}$ length

Teflon pipe-thread tape
Small Parts, Inc. 6901 N.E. 3rd Avenue Miami, Florida 33138

Stock No. ORB-001

Small Parts, Inc. Stock No. WX000

Small Parts, Inc. Stock No. MN632-12B

Small Parts, Inc. Stock No. HTX-18

Small Parts, Inc. Stock No. HTX-20TW

Local plastics supplier

Local hardware store 


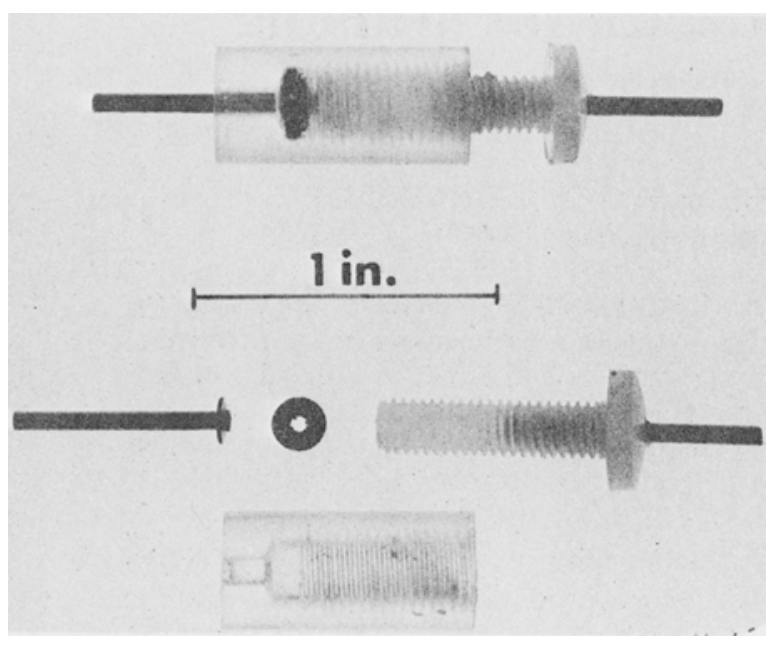

Figure 1. Construction of low-force swivel connector. Left: completed swivel; center: screw cap, $O$ ring, and rotating tube; right: swivel body.

if a jig is used to hold the screw. The jig is drilled and tapped in the same way as the swivel body, except that a No. 55 drill is substituted for the No. 60 drill. If the hole is not properly centered, it may be necessary to countersink the lower end of the screw slightly to allow room for the flared end of the rotating tube to turn. The 18-g piece of hypodermic tubing is forced into the hole in the screw to a depth of $6 \mathrm{~mm}$ by holding it in a pin vise or spare drill chuck and pushing it into the hole with a rotating motion. The entire screw cap is then threaded onto the swivel body until it sits snugly onto the washer and $\mathbf{O}$ ring. A leak-proof seal is insured by wrapping two layers of Teflon thread-seal tape around the screw cap before installing it.

The swivel is now complete. If it binds while turning, the screw cap should be loosened slightly; if leaks are observed around the exit point of the rotating tube, the screw cap should be tightened slightly.

A drill press and vise should be used for all drilling; it is all but impossible to drill holes in the swivel body with sufficient precision using a hand drill. Also, acrylic binds to metal when hot. This ruins both the swivel body and cutting tool. Overheating can be prevented by drilling and tapping the acrylic a little at a time and lubricating with light machine oil (e.g., Three-in-One oil).

The swivel can be connected to the infusion system in a number of ways. The simplest method is to slide a piece of thick-walled silicon rubber tubing (e.g., Ronsil Silitube, Base 10W/5CAB, Ronsil Rubber Products, Belle Mead, New Jersey 08502) over the needle tube exiting either end of the swivel, and slide the infusion system tubing into the other end of the silicon rubber tubing.

(Received for publication December 26, 1976; revision accepted February 26, 1977.) 